ADLFI. Archéologie de la France -

INFORMATIONS

Informations

une revue Gallia

Midi-Pyrénées | 1991

\title{
Canton de Bretenoux
}

\section{(2) OpenEdition \\ Journals}

Édition électronique

URL : http://journals.openedition.org/adlfi/10208

ISSN : 2114-0502

Éditeur

Ministère de la culture

Référence électronique

"Canton de Bretenoux ", ADLFI. Archéologie de la France - Informations [En ligne], Midi-Pyrénées, mis en ligne le 01 mars 1997, consulté le 03 mai 2019. URL : http://journals.openedition.org/adlfi/10208

Ce document a été généré automatiquement le 3 mai 2019.

(c) Ministère de la Culture et de la Communication, CNRS 


\section{Canton de Bretenoux}

Date de l'opération : 1991 (PR)

Inventeur(s) : Sarraza Fabienne

1 Un mémoire de maîtrise portant sur l'occupation du sol au Moyen Âge dans le canton de Bretenoux (seize communes) a permis de faire le point sur l'état des connaissances de ce secteur du nord-est du département, situé à la limite sud de la Corrèze.

2 Cette recherche, faite uniquement à partir des sources écrites et de la bibliographie existante, a été l'occasion de réactualiser l'ensemble des données acquises jusqu'alors à partir des cartulaires de l'abbaye de Beaulieu, des pouillés de la province de Bourges (XIV ${ }^{\mathrm{e}}$ s.) et ceux du diocèse de Cahors (XVies.), des cadastres des XVII ${ }^{e}$ s. et XVIII ${ }^{e}$ s., des monographies paroissiales et communales du XIX $\mathrm{s}$.

3 En dehors de sites antiques déjà signalés, comme l'habitat en grotte du Premier Âge du fer de Gintrac, Le Tribunal (Gallia, 1970: 428-429) ou celui mal interprété de BelmontBretenoux (oppidum ? à double enceinte de fossés) qui est sans aucun doute un site fortifié d'époque médiévale, il ne reste à signaler que les vestiges d'un établissement galloromain (murs, sol de mortier de chaux, tegulae, fragments de colonnes en grès) qui attestent l'ancienneté de l'occupation en plein centre du village de Gintrac.

4 Entre les $\mathrm{IX}^{\mathrm{e}} \mathrm{s}$. et $\mathrm{X}^{\mathrm{e}} \mathrm{s}$., plusieurs mentions tirées du cartulaire de Beaulieu signalent des villae (Bonneviolle, Félines, Biars, Bretenoux, Cahus, Glanes, Sepval) et on peut encore faire état de cinq villages ecclésiaux (Gagnac, Tautiac, Glanes, Cornac, Cahus), de villages castraux (Castelnau et Teyssieu) des XII ${ }^{e}$ s. et XIII ${ }^{e}$ s. et de deux bastides (Bretenoux a été fondée en 1277 et Puybrun, en 1282). 
INDEX

Index chronologique : Antiquité romaine, Moyen Âge* Index géographique : Midi-Pyrénées, Lot (46), Bretenoux operation Prospection (PR) 